Olivet Nazarene University

Digital Commons@ Olivet

Faculty Scholarship - Psychology

Psychology

$2-2013$

\title{
Political Attitudes Bias the Mental Representation of a Presidential Candidate's Face
}

\author{
Alison I. Young \\ Olivet Nazarene University, aiyoung@olivet.edu \\ Kyle G. Ratner \\ Ohio State University - Main Campus, ratner.8@osu.edu \\ Russell H. Fazio \\ Ohio State University - Main Campus, fdazio.11@osu.edu
}

Follow this and additional works at: https://digitalcommons.olivet.edu/psyc_facp

Part of the Applied Behavior Analysis Commons, Cognition and Perception Commons, Experimental Analysis of Behavior Commons, Political Science Commons, and the Social Psychology Commons

\section{Recommended Citation}

Young, A. I., Ratner, K. G., \& Fazio, R. H. (2013). Political attitudes bias the mental representation of a presidential candidate's face. Psychological Science, 24, 503-510.

This Article is brought to you for free and open access by the Psychology at Digital Commons @ Olivet. It has been accepted for inclusion in Faculty Scholarship - Psychology by an authorized administrator of Digital Commons @ Olivet. For more information, please contact

digitalcommons@olivet.edu. 
Political Attitudes Bias the Mental Representation of a Presidential Candidate’s Face

Alison I. Young, Kyle G. Ratner, and Russell H. Fazio

The Ohio State University, 1835 Neil Avenue, Columbus, OH 43210, USA

young.1415@osu.edu, ratner.8@osu.edu,fazio.11@osu.edu

Psychological Science, in press

Correspondence concerning this article should be addressed to Russell H. Fazio, Department of Psychology, Ohio State University, 1835 Neil Avenue, Columbus, Ohio, 43210. Email:

fazio.11@osu.edu; Telephone: (614) 688-5408; Fax: (614) 688-5414. 


\begin{abstract}
Using a technique known as reverse correlation image classification, we demonstrate that the physical face of Mitt Romney represented in people's minds varies as a function of their attitudes toward Mitt Romney. This provides evidence that attitudes bias how we see something as concrete and well-learned as the face of a political candidate during an election. Practically, this implies that citizens may not merely interpret political information about a candidate to fit their opinion, but that they may construct a political world where they literally see candidates differently.
\end{abstract}

Keywords: attitudes, construal, face perception, social perception 
Political Attitudes Bias the Mental Representation of a Presidential Candidate’s Face

Do Karl Rove and Arianna Huffington picture the same Mitt Romney? Do Republicans and Democrats have the same idea as to what Romney’s face looks like? It is easy to understand how people’s political views could bias their judgments of a candidate. However, one might expect that the mental image of something as concrete and well-known as a presidential candidate's face during an election season, a time during which that face is repeatedly presented to both Republicans and Democrats ad nauseum, would be a veridical representation free of bias. We provide evidence using a technique known as reverse correlation image classification that in the swing state of Ohio during the 2012 presidential election, Mitt Romney's physical face in the minds of Republicans was different from his face in the minds of Democrats.

In the pivotal battleground state of Ohio, the Democratic and Republican presidential campaigns spent a combined \$150 million on television advertising between April 11 and November 14, 2012 - the third-highest amount in the country (Andrews, Keating, \& Yourish, 2012). The city of Columbus, in particular, was inundated with almost 40,000 ads in that time, prompting Celeste Katz, a writer for the New York Daily News, to remark, "If you live in Ohio, good luck trying to tune out the election” (Katz, 2012). In the midst of this commercial-heavy campaign season, people were saturated with images of each candidate. As a result, residents of Columbus, Ohio during November, 2012 should have developed well-learned representations of what each candidate looked like physically.

Could one's mental representation of something as frequently-presented and well-known as a presidential candidate’s face during an election month in a swing-state be biased as a function of one's attitudes? Attitudes have been shown to bias the construal of objects and events (e.g., Hastorf \& Cantril, 1954; Lord, Ross, \& Lepper, 1979; Fazio \& Williams, 1986). However, 
in most cases, these objects/events are relatively ambiguous. A rough football tackle could be an infraction or not (Hastorf \& Cantril, 1954). A tennis shot close to the baseline could be in or out (Fazio, Roskos-Ewoldsen, \& Powell, 1994). What about less ambiguous objects? Recently, Caruso, Mead, \& Balcetis (2009) found that partisanship predicted whether an individual rated an image with artificially darkened skin as better representing Barack Obama than his actual image. If attitudes can bias the mental representation of skin tone, might they even influence the representation of a specific face? Perhaps not, given that faces attract more perceptual attention than other objects (Birmingham \& Kingstone, 2009; Yarbus, 1967). Furthermore, during an intense campaign in which people are flooded with images of Romney, representations of his face should be particularly clear. Finally, although partisanship may affect construals along a single dimension (skin darkness), presumably as a consequence of the greater negativity associated with darker skin tone, political attitudes may not be powerful enough to bias multidimensional facial representations and the extent to which they actually appear more/less appealing.

The following experiment tested the potential influence of attitudes by first assessing what Romney's face looked like in the minds of Ohio State undergraduates using a technique known as reverse correlation image classification. This data-driven method uses participants' classification of stimuli to obtain an “approximation of participants’ subjective internal representation” (Todorov, Dotsch, Wigboldus, \& Said, 2011) of a given face, allowing us to peer into the minds of participants and see what Romney looks like to them. This method has been used previously to relate a person’s prejudice regarding a social group (Moroccans) to the criminality and trustworthiness of that person's mental representation of a prototypical member of the group (Dotsch, Wigboldus, Langner, \& van Knippenberg, 2008). We sought to build on 
this finding by examining whether a person's memory regarding the face of a specific, welllearned individual (Romney) might relate to attitudes toward that individual. Once estimates of participants’ mental representations of Romney’s face were generated, they were rated by judges to assess whether they varied in a systematic and meaningful way.

The two variables on which we hypothesized these generated faces would vary were overall positivity and trustworthiness. Trustworthiness was one characteristic of Mitt Romney that was called into question during the election (Moody, 2012). A Quinnipiac poll (October 31, 2012) showed that although Ohio voters were just as likely (if not more so) to think that Romney was competent as they were Obama (64\% of respondents thought Romney had strong leadership qualities; 58\% thought Obama did), they were less likely to think that Romney was trustworthy (45\% thought Romney was honest and trustworthy; 54\% thought Obama was). It was particularly relevant, then, to investigate whether representations of Romney’s face might look more or less trustworthy depending on participants’ level of support for the candidate.

We hypothesized that the mental representations of the face of Romney in the minds of participants who supported the candidate, voted for him, etc. would look a) more trustworthy and b) more positive overall than his face in the minds of detractors.

\section{Method}

Our method, based on that used by Dotsch et al. (2008), consisted of two phases. In the first, participants completed a face categorization task, the goal of which was to estimate each participant's mental representation of Mitt Romney using the reverse correlation image classification method. These participants then completed items assessing their support for Romney, their voting intentions/behavior, and their political orientation. In the second phase, separate samples of independent judges rated the images of Romney that had been generated in 
phase one. These ratings allowed us to objectively determine whether mental representations of Romney’s face differed meaningfully for supporters and non-supporters.

\section{Participants}

148 undergraduates (87 males) at The Ohio State University in Columbus, Ohio participated in phase one for course credit. Data were collected directly preceding (November 15) and directly following (November 13-28) the 2012 presidential election, which took place on November 6th.

Phase two participants included three samples of adults from Amazon.com’s Mechanical Turk website (total N=213; 131 males) who rated averaged photos of Romney in pairs and nine volunteers who rated all 148 images generated by each phase one participant.

\section{Stimuli for Face Classification Task}

All faces were generated from the same base image - a photograph of Romney selected from an online search because he is facing forward and his expression is neutral. The image was converted to grayscale and cropped to Romney’s face. To change the appearance of his face on a given trial, we superimposed noise patterns on the image, slightly altering the look of his facial features (see Figure 1). The noise patterns varied on 4,092 parameters consisting of superimposed truncated sinusoid patches spanning two cycles in six orientations $\left(0^{\circ}, 30^{\circ}, 60^{\circ}\right.$, $90^{\circ}, 120^{\circ}$, and $\left.150^{\circ}\right) \mathrm{x}$ five spatial frequencies $(1,2,4,8$, and 16 , patches per image) $\mathrm{x}$ two phases $(0, \pi / 2)$ with random contrasts (amplitudes). All images were 256x256 grayscale pixels. 


\section{Which looks more like Mitt Romney?}
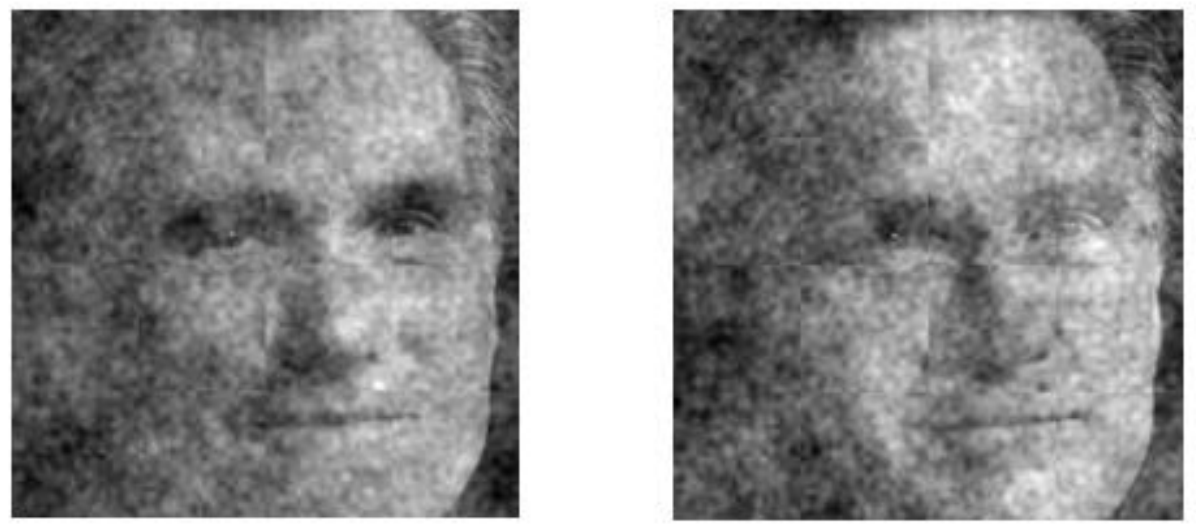

Fig. 1. An example of face stimuli used in the reverse correlation task. Participants selected which of the two images looked more like Romney for 450 image pairs.

\section{Procedure: Phase One}

Face classification task. Phase one participants learned that the goal of the study was to see how well people identify the faces of well-known individuals. Specifically, we told them we wanted to see how accurately they could identify the image that looked more like Mitt Romney. Participants then completed 450 trials during which a pair of photographs of Romney appeared, one on the left, one on the right, and pressed a key to indicate which looked more like Romney. The photographs consisted of either a random noise pattern or its inverse superimposed over the base face. The side on which the inverse-noise image appeared was counterbalanced across trials. All participants were presented with the same noise patterns. Trial order was randomized. 
Attitude assessments. After the classification task, participants completed a series of items assessing their a) support for Romney, b) voting intentions/behavior, and c) political orientation.

Support for Romney was a component score based on 14 items, six of which assessed agreement with Romney’s position on various policy issues (e.g., “To what extent do you agree with Mitt Romney’s position on jobs?”). Four assessed participants’ opinions regarding Romney’s leadership qualities (e.g., “To what extent do you think Mitt Romney is a strong leader?”). The final four items assessed emotions evoked by Romney (e.g., “To what extent does Mitt Romney make you feel hopeful?”). All 14 items used a 6-point scale from “Not at all” to “Very much.” A parallel set of filler items involved Obama as the target. Because the reliability of the 14 Romney items was high $(\alpha=0.94)$, we generated a component score for each participant based on a principal components analysis in which one factor was retained (eigenvalue=9.18, variance explained=65.55\%, next highest eigenvalue=1.26). This indexed participants’ overall support for Romney.

Voting intentions were assessed slightly differently depending on whether individuals participated before or after Election Day. Prior to the election, participants responded to two items assessing the likelihood that if they were to vote today, they would vote for Mitt Romney (Barack Obama) on a 7-point scale from "Not at all likely” to "Very likely.” We calculated a difference score between their likelihood of voting Romney versus Obama (pro-Romney if greater than zero, pro-Obama if less than zero). Nine participants were excluded from this particular analysis for not indicating a clear voting intention. Participants run after the election responded to a single item: "Who did you vote for in the presidential election?” Participants' options were “Barack Obama,” “Mitt Romney,” or “a third-party candidate.” Analyses based on 
this item omitted participants who did not vote $(\mathrm{N}=24)$ or who voted for a third-party candidate $(\mathrm{N}=1)$.

We assessed political orientation using four items which asked participants the extent to which political ideology labels (Democrat, Liberal, Republican, or Conservative) described them on a 7-point scale from “Weak” to "Strong," with a "Not Applicable” option. We averaged the two politically-left labels and subtracted them from the average of the two politically-right labels.

Assessing participants’ mental representations of Mitt Romney’s face. In order to generate an estimate of Romney's face in the minds of each participant, we utilized reverse correlation data reduction techniques. Reverse correlation image classification assumes that, on each trial, participants match their mental image of the target to the two faces presented on the screen, choosing the face which most closely resembles that image. Past research has demonstrated that by averaging over several hundred trials, this method can provide an estimate of a person’s mental representation of a target object (Mangini \& Biederman, 2004; Dotsch et al., 2008).

We generated two types of face estimates: participant-level and group-level. Participantlevel images were generated by averaging all 450 noise patterns a given participant selected and then superimposing that average over the original base photograph of Romney, providing an estimate of each individual's mental representation of Romney’s face (148 in all, one per participant). Group-level images provided an estimate of Romney’s face for subgroups of participants: the average noise patterns for people who belonged to a specific category (e.g., all Republican participants) were averaged together and superimposed over the original base 
photograph. These provided estimates not of the mental representation of Romney in the minds of each individual, but in the minds of a group of like-minded people.

The specific variables we grouped people by were a) support for Romney, as indexed by the component score described earlier, b) voting intentions/behavior, and c) political orientation. We generated 12 group-level images in total. Two of the “support for Romney” group-level images were averages of the average noise patterns of pre-election participants high in support (+1 SD and above; $\mathrm{N}=15$ ) versus low in support for Romney (-1 SD and below; $\mathrm{N}=15)$, and two were of post-election participants high (+1 SD and above; $\mathrm{N}=15)$ versus low in support ( $-1 \mathrm{SD}$ and below; $\mathrm{N}=17$ ). Two of the "voting intentions/behavior" group-level images were averages of the average noise patterns of pre-election participants more likely to vote for Romney $(\mathrm{N}=29)$ versus Obama $(\mathrm{N}=31)$, and two were of post-election participants who voted Romney $(\mathrm{N}=21)$ versus Obama (N=32). Finally, two “political orientation” group-level images were based on preelection participants who identified more as Republicans $(\mathrm{N}=23)$ versus Democrats $(\mathrm{N}=26)$, based on a difference score, and two were based on post-election participants who identified more as Republicans ( $\mathrm{N}=26)$ versus Democrats $(\mathrm{N}=37)$.

\section{Procedure: Phase Two}

This phase focused on indexing whether participants' mental representations of Mitt Romney's face were biased in line with their attitudes toward the candidate. Judges rated either the participant- or group-level Romney faces on various dimensions.

Ratings of participant-level estimates. Nine volunteers rated images representing each phase one participant's mental representation of Romney $(\mathrm{N}=148)$ as to how trustworthy they thought Romney looked (eight-point scale from 0 "Not at all trustworthy" to 7 "Extremely trustworthy”). 
Ratings of group-level estimates. Various group-level images (High vs. Low Support for Romney pre- and post-election; Intention to Vote Romney vs. Obama pre-election; Voted Romney vs. Obama post-election; More Republican vs. More Democrat pre- and post-election) were presented to three separate samples $(\mathrm{N}=70, \mathrm{~N}=72$, and $\mathrm{N}=71)$ on Amazon's Mechanical Turk (MTurk). MTurk has been shown to provide data of similar quality and reliability to data collected in a controlled laboratory environment (Paolacci, Chandler, \& Ipeirotis, 2010; Buhrmester, Kwang, \& Gosling, 2011). Across all three samples, 82 women and 131 men participated (mean age=31.61, range 18-69). These participants, naïve to how the faces were generated, were paid between 25 and 50 cents for five minutes of their time. They saw a given pair of images, one on the left and one on the right (counterbalanced), and were asked to indicate in which of the two photographs Romney looked more trustworthy, competent, and caring (6point scale from "Looks much more trustworthy/competent/caring in the photo on the LEFT" to “Looks much more trustworthy/competent/caring in the photo on the RIGHT”). The order of these three ratings was counterbalanced. For the final item, we asked participants to make a global judgment (“Overall, in which image does Mitt Romney look better?”) on a 6-point scale from "Mitt Romney looks much better in the LEFT image” to "Mitt Romney looks much better in the RIGHT image.”

\section{Results}

We first report correlations between the participant variables (support for Romney, voting behavior, and political orientation) and the judged trustworthiness of their mental representation of Romney. We then report differences between the average representations of the candidate in the eyes of certain participant groups (high support vs. low support, voted Romney vs. Obama, 
Republican vs. Democrat). See the supplemental materials for additional analyses demonstrating that participation prior to versus following the election had no effect.

Predicting the trustworthiness of participant-level estimates

Phase one participants’ individual component score (support for Romney) was significantly correlated with the judged trustworthiness of their mental representation of Romney, $r(147)=0.23, p=0.006$, suggesting that the more participants supported the candidate, the more trustworthy their mental representation of him appeared to be. This correlation and all following analyses excluded one participant as an outlier, but the correlation (and all other effects) remains if that outlier is included $(r(148)=0.16, p=0.025)$. See Figure 2 for a scatterplot of this correlation. 


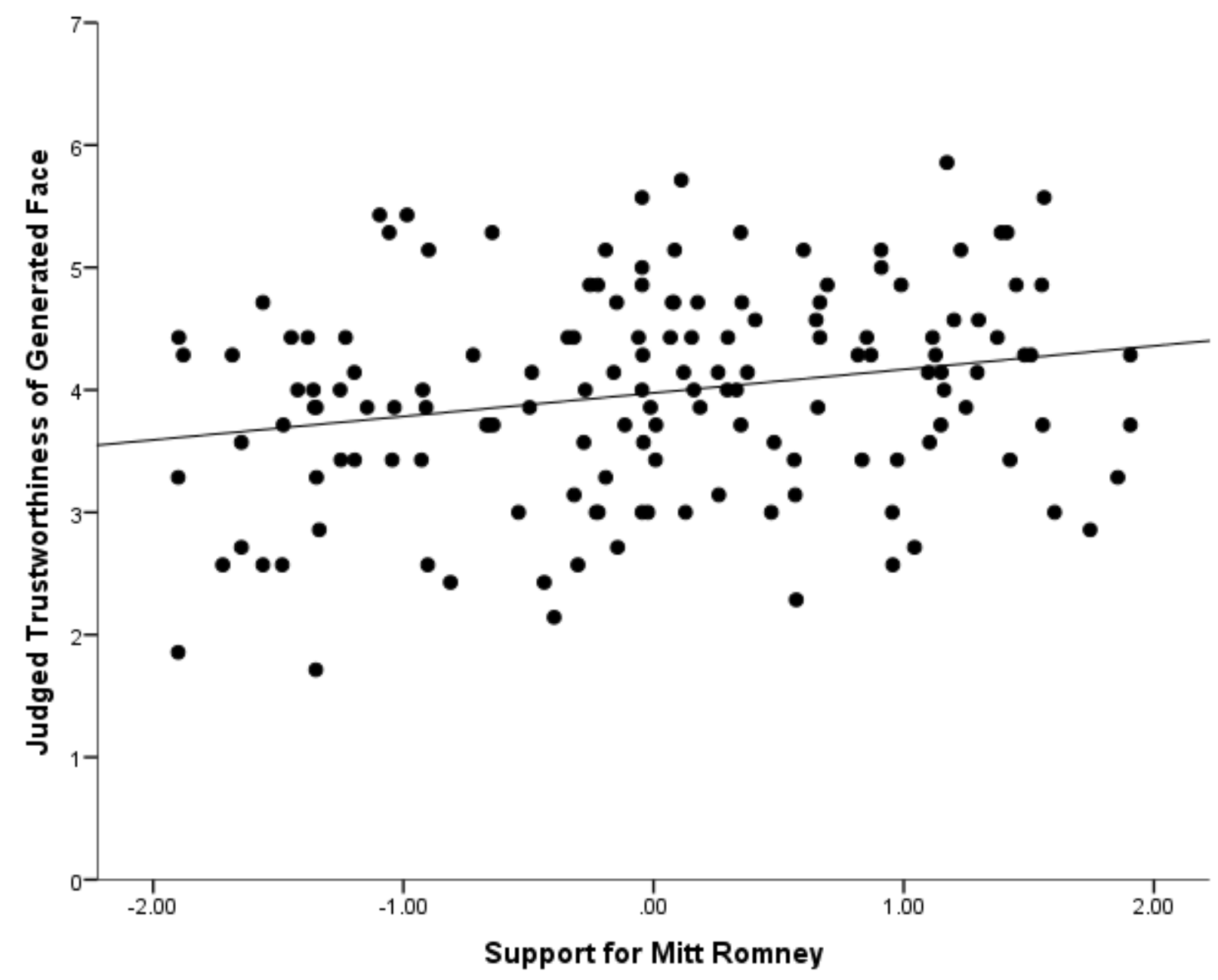

Fig. 2. Scatterplot of the correlation between each participant's support for Mitt Romney (as indexed by a component score based on a series of items) and the judged trustworthiness of the image that participant generated.

We analyzed whether participants who said they will vote/actually voted for Romney generated a more trustworthy-looking image than those who said they will vote/actually voted for Obama. This analysis excluded 33 participants who had no preference, did not vote, or voted 
for a third-party candidate. Participants who said they will vote/voted for Romney generated a more trustworthy-looking image $(M=4.24)$ than participants who said they will vote/voted for Obama (M=3.77), $t(111)=2.90, p=0.004$. This difference remained significant if we included the outlier, $t(112)=2.53, p=0.013$.

Finally, we correlated participants’ political orientation (excluding 12 participants who were independent or did not indicate a clear political orientation) with the judged trustworthiness of their representation of Romney. This correlation was significant, $r(136)=0.28, p=0.001$, suggesting that the more politically right participants reported they were, the more trustworthy their mental representation of Romney.

The supplemental materials include analyses conducted at the level of the individual rater, which revealed the same effects as above. Also included are details of a multiple regression showing that all three predictors - support, voting, and political orientation - together accounted for a significant proportion of the variance $\left(R^{2}=0.09, F(3,103)=3.44, p=0.02\right)$, although none did so uniquely.

\section{Group-level differences}

The two High (averaged from either the 15 pre- or 15 post-election participants +1 SD and above) vs. Low Support for Romney (averaged from either the 15 pre- or 17 post-election participants -1 SD and below) pairs of group-level images were rated by 71 MTurk participants. Responses on the four 6-point items (trustworthy, caring, competent, and overall judgment) were recoded such that higher numbers indicated a relative preference for the pro-Romney composite face. Because these items were identically worded for the pre-election and the post-election pairs, we averaged the two types (pre- and post-election) together. While the images did not differ in perceived trustworthiness $(p=0.22)$, caring $(p=0.10)$ or competence $(p=0.69)$, they did 
differ overall. A one-sample t-test against the scale midpoint of 3.5 revealed that, as predicted, the photograph of Romney based on phase one participants who supported the candidate more was rated as looking better overall than the photograph of Romney based on those who supported him less $(M=3.67, t(70)=2.04, p=0.045)$.

The Will Vote Romney (based on 29 pre-election participants) vs. Obama (based on 31) pair of group-level images were rated by a separate online sample $(\mathrm{N}=70)$ from the Voted Romney (based on 21 post-election participants) vs. Obama (based on 32) pair of group-level images ( $\mathrm{N}=72$ ). Because the items (trustworthy, caring, competent, and overall rating) were identically worded, even though the photos had been generated and rated by different participants, we collapsed across both samples to see if, overall, the Will Vote/Voted Romney photo of Romney was rated as more trustworthy/caring/competent/looking generally better than the Will Vote/Voted Obama photo of Romney. Although the images did not differ in terms of how caring or competent Romney looked (lowest $p=0.17$ ), they did differ with regard to how trustworthy and how good overall Romney looked. One-sample t-tests against the scale midpoint of 3.5 revealed that, as predicted, the photograph of Romney based on phase one participants who planned to vote/voted Romney was rated as more trustworthy $(M=3.67, t(141)=2.00$, $p=0.048)$ and as looking better overall $(M=3.74, t(141)=2.39, p=0.02)$ than the photograph based on phase one participants who planned to vote/voted Obama.

Finally, the More Republican (based on either 23 pre-election or 26 post-election participants) vs. More Democrat (based on either 26 pre-election or 37 post-election participants) pairs of group-level images were also rated by the same two online samples who had rated the Will Vote/Voted images (above). Again, one of the samples ( $\mathrm{N}=70)$ rated the pair generated by pre-election participants in phase one, and the other sample $(\mathrm{N}=72)$ rated the pair generated by 
post-election participants. We again collapsed across both samples to see if, overall, the Republican photo of Romney was rated as more trustworthy/caring/competent/looking better overall than the Democrat photo of Romney. The images did not differ in terms of how caring or competent Romney looked (lowest $p=0.07)$. However, as before, the images differed with regard to how trustworthy and how good overall Romney looked. One-sample t-tests against the scale midpoint of 3.5 revealed that, as predicted, the photograph of Mitt Romney generated by phase one Republican participants was rated as more trustworthy $(M=3.73, t(141)=2.52, p=0.013)$ and as looking better overall $(M=3.85, t(141)=3.58, p<0.0001)$ than the photograph generated by Democrat participants (see Figure 3).

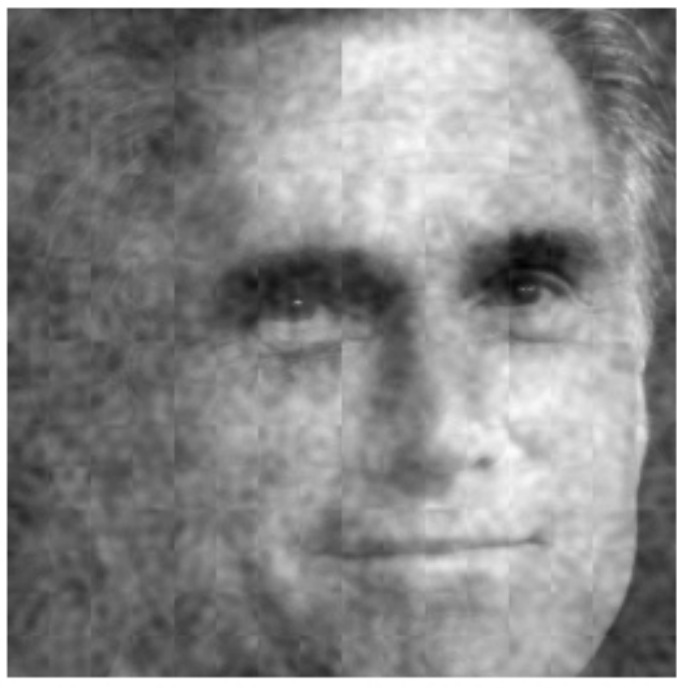

Image generated by participants who identified as Democrats

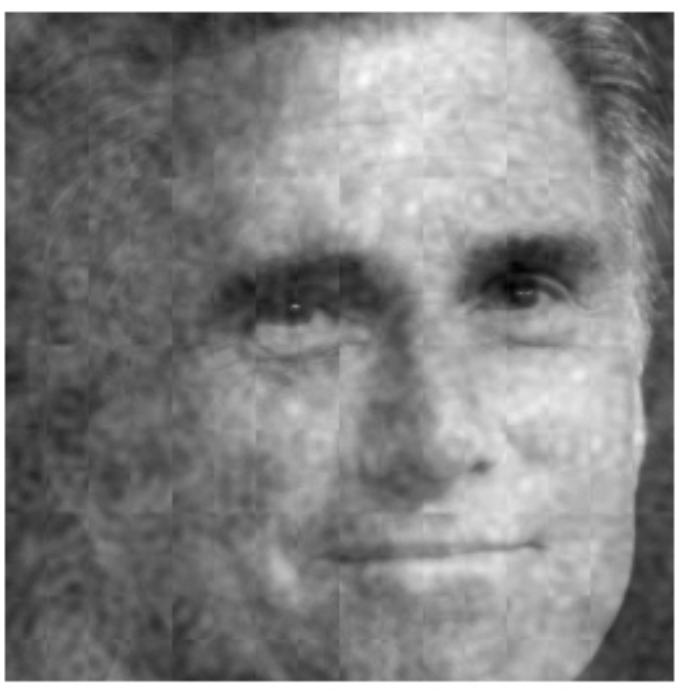

Image generated by participants who identified as Republicans

Fig. 3. The two Romney images generated by post-election participants who identified as

Democrat versus Republican. Note that the difference is subtle, as many of the online judges remarked. Nevertheless, they rated the face generated by participants who identified as Republicans as more trustworthy and as looking better overall. 
The supplemental materials detail a meta-analysis of the three group-level image comparisons (support, voting, and political orientation), providing evidence that the pro-Romney image was rated as significantly more trustworthy, caring, and overall better than the antiRomney image.

\section{Discussion}

The above experiment provides evidence that our subjective mental representations of an object to which we are exposed frequently and whose characteristics should be relatively unambiguous can be biased in line with political attitudes. Though voters in the swing state of Ohio were exposed to countless political advertisements and thus had a very good idea of what Romney's face looked like, we consistently found that his face in the minds of supporters looked more trustworthy and better overall than his face in the minds of detractors.

The reverse correlation method was particularly useful in this case because it provided an estimate of something which would be difficult to approximate using self-report measures: the mental representation of a specific individual's face in the mind of a participant. We were, in essence, peering into the participants' mind's eye and estimating what they pictured when they imaged Romney’s face. Participants were not confronted with a direct query regarding Romney’s face (e.g., “What does Romney’s face look like to you? How trustworthy is that face?”). Instead, the method bypassed any reliance upon participants' judgments of how trustworthy or attractive their own visual representations of Mitt Romney’s face were. As such, it allowed us to obtain an estimate of participants’ visual images untarnished by the demand characteristics that can arise from a direct query. It also overcame any difficulty participants might have experienced if required to visualize their representations entirely on their own unaided by the stimulus images. 
One could suggest that participants are responding to each trial directly on the basis of their attitude, e.g., selecting the more positive of the two images because they have more positive attitudes toward Romney. We find this improbable given that participants were told explicitly that we were interested in their accuracy in identifying which image looked more like the candidate. In addition, during every trial, the question "Which looks more like Mitt Romney?” was presented on the screen, emphasizing that we were asking them to choose which image was more similar to the actual candidate, not which image looked better or more trustworthy. Moreover, in contrast to cases in which the reverse correlation method is used to assess the face of a prototypical group member, the present participants certainly would have had a concrete mental image to consult when making their selections.

In sum, a variety of findings provide evidence consistent with the proposition that participants' mental representations of the face of Mitt Romney were influenced by their political attitudes. Attitudes may have directly biased their representations. However, an additional possibility is that attitudes may have done this indirectly via selective exposure (Frey, 1986). That is, perhaps supporters of Romney preferentially watched commercials that were proRomney and detractors preferentially watched commercials that were anti-Romney and perhaps these ads differed with respect to the nature of the Romney face they displayed. We find this somewhat implausible, since Ohio voters were saturated with advertisements and unlikely to have been able to limit their exposure to the advertisements of a single campaign. In addition, a literature search did not succeed in uncovering empirical evidence that political advertisements use photographs of an opponent in which that opponent actually looks different (e.g., less trustworthy). Nevertheless, further research should focus on whether selective exposure contributes to the phenomenon revealed by the present research. 
This work provides evidence that political attitudes (i.e., support for a candidate, political orientation) predict variability in the mental representation of something so concrete and familiar that it is seemingly immune to bias: a well-known presidential candidate's face in a swing state in the heat of an election campaign. During the month of the presidential election, variations in participants’ representations of Mitt Romney’s face were related to their support for the candidate, their political affiliation, and their voting behavior. This implies that our attitudes have power to shape the world we see, even to the point of changing our mental representation of a person to whom we are exposed very frequently, providing what appears to be additional confirmation of those very attitudes. That attitudes can bias 'reality' in the context of such a well-known, specific referent is a striking demonstration of their power. 
A. I. Young developed the study concept with help from K. G. Ratner regarding the reverse correlation method and R. H. Fazio regarding the influence of attitudes. All authors contributed to the design. A. I. Young and K. G. Ratner generated the stimuli. A. I. Young programmed the experiment and collected the data. A. I. Young performed the data analysis with help from K. G. Ratner under the supervision of R. H. Fazio. A. I. Young drafted the paper and K. G. Ratner and R. H. Fazio provided critical revisions. All authors approved the final version of the paper for submission. 


\section{Acknowledgements}

We thank Eva Pietri, Matt Rocklage, Pete Zunick, Elise Bui, and the Group for Attitudes and Persuasion at Ohio State University for feedback on this experiment. We also thank Lindsay Johnston for help in data collection and Ron Dotsch for providing MATLAB code. 


\section{References}

Andrews, W., Keating, D., \& Yourish, K. (2012, November 14). Mad money: TV ads in the 2012 presidential campaign. The Washington Post. Retrieved from http://www.washingtonpost.com/wp-srv/special/politics/track-presidential-campaign-ads2012/

Birmingham, E. \& Kingstone, A. (2009). Human social attention: A new look at past, present and future investigations. The Year in Cognitive Neuroscience: Annals of the New York Academy of Sciences, 2009, 118-140.

Buhrmester, M., Kwang, T., \& Gosling, S. D. (2011). Amazon’s Mechanical Turk: A new source of inexpensive, yet high-quality, data? Perspectives on Psychological Science, 6, 3-5.

Caruso, E. M., Mead, N. L., \& Balcetis, E. (2009). Political partisanship influences perception of biracial candidate's skin tone. Proceedings of the National Academy of Sciences of the United States of America, 106, 20168-20173.

Dotsch, R., Wigboldus, D. H. J., Langner, O., \& van Knippenberg, A. (2008). Ethnic out-group faces are biased in the prejudiced mind. Psychological Science, 19, 978-980.

Fazio, R. H., Roskos-Ewoldsen, D. R., \& Powell, M. C. (1994). Attitudes, perception, and attention. In P. M. Niedenthal \& S. Kitayama (Eds.), The heart's eye: Emotional influences in perception and attention (pp. 197-216). New York: Academic Press.

Fazio, R. H. \& Williams, C. J. (1986). Attitude accessibility as a moderator of the attitudeperception and attitude-behavior relations: An investigation of the 1984 presidential election. Journal of Personality and Social Psychology, 51, 505-514.

Frey, D. (1986). Recent research on selective exposure to information. Advances in Experimental Social Psychology, 19, 41-80. 
Hastorf, A. H. \& Cantril, H. (1954). They saw a game: A case study. Journal of Abnormal and Social Psychology, 49, 129-134.

Katz, C. (2012, October 14). Nonstop barrage of political ads flood the airwaves in key battleground state of Ohio. New York Daily News. Retrieved from http://www.nydailynews.com/news/election-2012/ad-nauseum-ohio-article-1.1182946

Lord, C. G., Ross, L., \& Lepper, M. R. (1979). Biased assimilation and attitude polarization: The effects of prior theories on subsequently considered evidence. Journal of Personality and Social Psychology, 37, 2098-2109.

Mangini, M. C. \& Biederman, I. (2004). Making the ineffable explicit: Estimating the information employed for face classifications. Cognitive Science, 28, 209-226.

Moody, C. (2012, October 23). Obama in Ohio: Romney is not to be trusted. Yahoo News. Retrieved from http://news.yahoo.com/blogs/ticket/obama-ohio-romney-not-trusted214333569--election.html

Paolacci, G., Chandler, J., \& Ipeirotis, P. (2010). Running experiments on Amazon Mechanical Turk. Judgment and Decision Making, 5, 411-419.

Quinnipiac University (2012, October 31). Obama up in Ohio; Florida, Virginia too close to call, Quinnipiac University/New York Times/CBS News swing state poll finds. Retrieved from http://www.quinnipiac.edu/institutes--centers/polling-institute/presidential-swingstates-(fl-oh-and-pa)/release-detail?ReleaseID=1812

Todorov, A., Dotsch, R., Wigboldus, D. H. J., \& Said, C. P. (2011). Data-driven methods for modeling social perception. Social and Personality Psychology Compass, 5, 775-791. Yarbus, A. L (1967). Eye movements and vision (B. Haigh, Trans.). New York: Plenum Press. 